\title{
Extracurricular research activities among senior medical students in Kuwait: experiences, attitudes, and barriers
}

\author{
Becher Al-Halabi' \\ Yousef Marwan² \\ Mohammad Hasan ${ }^{3}$ \\ Sulaiman Alkhadhari ${ }^{4}$ \\ 'Department of Surgery, Mubarak \\ Al-Kabeer Hospital, Ministry of \\ Health, Kuwait; ${ }^{2}$ Department of \\ Orthopaedic Surgery, Al-Razi Hospital, \\ Al-Sabah Medical Area, Ministry \\ of Health, Kuwait; ${ }^{3}$ Department of \\ Radiation Oncology, Kuwait Cancer \\ Control Center, Al-Sabah Medical \\ Area, Ministry of Health, Kuwait; \\ ${ }^{4}$ Department of Psychiatry, Faculty \\ of Medicine, Health Sciences Center, \\ Kuwait University, Kuwait
}

This article was published in the following Dove Press journal:

Advances in Medical Education and Practice

28 April 2014

Number of times this article has been viewed
Background: Research is the foundation of scientific advancement and improvement in quality of health care, which ensures the good health of the community. The aim of this study is to explore experiences, attitudes, and barriers of medical students in Kuwait University (KU) in regards to extracurricular research.

Methods: A questionnaire about extracurricular research activities (ie, any research activity that is not part of the required undergraduate curriculum, such as publishing a paper, research elective, etc) was distributed to 175 senior medical students (years 6 and 7). Descriptive and chi-square analyses were used to analyze the responses, considering a $P$-value of $<0.05$ as the cut-off level for significance. The main outcome was defined as taking part in any of the extracurricular research activities.

Results: Of the 150 participants (response rate $=85.7 \%), 26(17.3 \%), 68(45.3 \%), 52(34.7 \%)$, and $17(11.3 \%)$ had published their required medical school research, presented abstracts in conferences, conducted extracurricular research, and completed a research elective/course, respectively; $99(66.0 \%)$ took part in any of these activities. Participants who read medical journals regularly $(81 ; 54 \%)$ reported higher participation in extracurricular research activities than those who did not read journals $(P=0.003)$. Improving the availability of mentors for students' extracurricular research was ranked by the participants as the most important factor to improve their participation in extracurricular research (4.05/5.00).

Conclusion: Despite the lack of adequate support, extracurricular research activities among medical students of KU were comparable to students from other countries. Barriers for these activities should be addressed by KU medical educators in order to enhance research activities among the students.

Keywords: research, publication, undergraduate, medical education, medical students

\section{Introduction}

Research is imperative in the advancement and improvement of the quality of health care. As such, medical students are required to develop research skills. It has been shown that involvement in research activities allows medical students to gain skills in search methodology, critical appraisal, statistics, time management, and teamwork, thus improving patients' care. ${ }^{1-5}$ Moreover, getting involved in research and publishing scientific papers while attending a medical school increases the chances of students getting accepted in highly competitive residency training programs. ${ }^{4,6-8}$

A large number of medical students have reported that conducting research is challenging; however, interest in a specific field and career advancement were the strongest motivators. ${ }^{9,10}$ Lack of time and availability of supervisors, a perception that the student
Correspondence: Yousef Marwan Department of Orthopaedic Surgery, Al-Razi Hospital, Ministry of Health,

PO Box 24923, Safat 131 I0, Kuwait

$\mathrm{Tel}+96594060660$

Email yousefmarwan@hotmail.com
Advances in Medical Education and Practice 20|4:5 95-I0। 95

Dovepress

http://dx.doi.org/10.2147/AMEP.S61413 (c) (i) (5) 2014 Al-Halabi et al. This work is published by Dove Medical Press Limited, and licensed under Creative Commons Attribution - Non Commercial (unported, v3.0) License. The full terms of the License are available at http://creativecommons.org/licenses/by-nc/3.0/. Non-commercial uses of the work are permitted without any further permission from Dove Medical Press Limited, provided the work is properly attributed. Permissions beyond the scope of the License are administered by Dove Medical Press Limited. Information on
how to request permission may be found at: http://www.dovepress.com/permissions.php 
would not receive appropriate acknowledgement for effort spent in research activities, and the perception that researchers are isolated from clinical practice were common reasons for not conducting research among medical students. ${ }^{3,10}$

The Kuwait University (KU) medical curriculum is a 7-year program divided into a 4-year basic and a 3-year clinical sciences program. Evidence-based medicine (EBM) and research skills courses are part of both the basic sciences and clinical phases of the medical curriculum. Medical students start learning the basics of EBM, biostatistics, and epidemiology throughout the basic sciences phase, while they conduct a community medicine (CM) research project during an 8-week period of the clinical phase, with no obligation to publish their research projects. Students form small groups of 4 to 5 students to conduct their research, and the department of Community Medicine and Behavioural Sciences assigns research mentors and assistants to guide the groups throughout the steps of their project. This CM module is the course which exposes the students to research and basic concepts of public health and community medicine.

$\mathrm{KU}$ is focusing on the evaluation and improvement of the bedside teaching of their medical students; however, evaluating research and EBM education has not been done before. ${ }^{1-14}$ In this study, any research experience that was not part of the curriculum in medical school is defined as an extracurricular research activity that includes presenting research abstracts, publishing scientific papers or participating in research electives. Knowledge about the involvement of KU medical students in extracurricular research activities is lacking. Therefore, we aimed to explore the experiences of extracurricular research activities, study the attitude of the senior medical students towards research and publication, and investigate the barriers to acquiring competence in research practices among medical students in KU. The deficiency of research infrastructure that integrates undergraduate medical students in Kuwait suggests that there should be little student participation in extracurricular research activities. This presents an opportunity in comparing such students to their international peers in terms of these activities, aiming to understand if the lack of a support system for students' research would result in a lower participation in research activities.

\section{Methods}

This cross-sectional study conducted during November 2012 included medical students from KU who had completed their research projects (ie, sixth and seventh year medical students). During the academic year 2012/2013,91 and 95 students were enrolled in the sixth and seventh years of study respectively (a total of 186).

A self-administered questionnaire composed of three main sections was developed based on a comprehensive literature review and was pre-tested on 20 randomly selected students to ensure clarity of questions. ${ }^{2,3,9,10}$ Section I included 13 multiple choice, closed-ended questions about the sociodemographic characteristics and background information about the student's research and publication practice. Sections II and III consisted of questions about the student's attitude towards research and barriers against research practice, containing 11 and 13 questions, respectively. The students had to choose between yes or no for sentences about the attitude toward research, and were asked to rate possible barriers to their participation in extracurricular research activities using a scale ranging from 1 (strongly disagree) to 5 (strongly agree).

Written informed consent was obtained from each participant after proper explanation of the objectives of the study. Participants were assured of the confidentiality of the collected information. They were also assured that there would not be any harm if they declined to participate in the study. The study protocol and data collection instrument were ethically approved by Kuwait Institute for Medical Specialization, and permission to collect data from the students was obtained from the administration of the Faculty of Medicine of KU.

Data were entered and analyzed using Statistical Package for the Social Sciences (SPSS, version 17.0; PASW, SPSS Inc, Chicago, IL, USA). Frequencies and percentages were obtained for all variables to generate descriptive tables and figures. Chi-square analysis was performed to assess the association between students' participation in extracurricular research activities and their sociodemographic and academic characteristics, to understand if students with different academic performance or personal backgrounds would have different interests in research. A $P$-value of $<0.05$ was considered as the cut-off level for statistical significance.

\section{Results}

Of 175 students who were approached, 150 (87.5\%) agreed to participate in the study while the remaining $25(14.3 \%)$ did not offer any reason for declining. The sociodemographic and academic characteristics of the study sample are given in Table 1. Of the 150 participants, 88 (58.7\%) were female, $83(55.3 \%)$ aged 23 years or less, and 117 $(78.0 \%)$ were unmarried. With regard to their academic features, $87(58.0 \%)$ students were in their final year of study, 
Table I Sociodemographic and academic characteristics of medical students in Kuwait University during the academic year $2012 / 2013$

\begin{tabular}{|c|c|c|}
\hline Characteristic & $\mathbf{N}$ & (\%) \\
\hline \multicolumn{3}{|l|}{ Sex } \\
\hline Male & 62 & $(4 I .3)$ \\
\hline Female & 88 & $(58.7)$ \\
\hline \multicolumn{3}{|l|}{ Age (years) } \\
\hline$\leq 23$ & 83 & $(55.3)$ \\
\hline$>23$ & 67 & $(44.7)$ \\
\hline \multicolumn{3}{|l|}{ Marital status } \\
\hline Married & 33 & $(22.0)$ \\
\hline Not married & 117 & $(78.0)$ \\
\hline \multicolumn{3}{|l|}{ Year of study } \\
\hline Sixth year & 63 & $(42.0)$ \\
\hline Seventh year & 87 & $(58.0)$ \\
\hline \multicolumn{3}{|c|}{ Grade point average (out of 4 ) } \\
\hline$\leq 2.99$ & 123 & $(82.0)$ \\
\hline$\geq 3.00$ & 27 & $(18.0)$ \\
\hline \multicolumn{3}{|c|}{ Grade in community medicine module } \\
\hline$\geq 80 \%$ & 28 & $(18.7)$ \\
\hline$<80 \%$ & 122 & $(81.3)$ \\
\hline \multicolumn{3}{|c|}{ Decided a future career specialty } \\
\hline Not yet & 79 & $(52.7)$ \\
\hline Yes & 71 & $(47.3)$ \\
\hline \multicolumn{3}{|c|}{ Preferred future specialty* } \\
\hline Surgical & 21 & $(29.6)$ \\
\hline Medical & 29 & $(40.8)$ \\
\hline Other & 21 & $(29.6)$ \\
\hline \multicolumn{3}{|c|}{ Preferred place of residency* } \\
\hline Kuwait & 18 & $(25.4)$ \\
\hline Outside Kuwait & 53 & (74.6) \\
\hline \multicolumn{3}{|c|}{ Regularly read journal articles } \\
\hline No & 81 & $(54.0)$ \\
\hline Yes & 69 & $(46.0)$ \\
\hline
\end{tabular}

Table 2 Extracurricular research activities of medical students in Kuwait University during the academic year 2012/2013

\begin{tabular}{lll}
\hline Characteristic & N & (\%) \\
\hline Published the research project of the CM module & 26 & $(17.3)$ \\
Presented an abstract in a conference & 68 & $(45.3)$ \\
Participated in research other than CM project & 52 & $(34.7)$ \\
(currently or in the past) & & \\
Joined extracurricular research courses/electives & 17 & $(11.3)$ \\
Took part in any of the above research related & 99 & $(66.0)$ \\
activities (overall) & & \\
\hline
\end{tabular}

Abbreviation: $\mathrm{CM}$, community medicine.

$123(82.0 \%)$ had a grade point average (GPA) of $<3.00,122$ $(81.3 \%)$ scored $<80.0 \%$ in their CM module, and $79(52.7 \%)$ had not decided a future career specialty, while $71(47.3 \%)$ had made such a decision. Of the 71, 29 (40.8\%) preferred a medical future specialty and $53(74.6 \%)$ were planning to complete their postgraduate education/residency outside of Kuwait. Of the 150 participants, 81 (54.0\%) students read medical journals regularly (ie, following at least one journal's issues and updates).

Overall, $99(66.0 \%)$ of the students had participated in extracurricular research activities (Table 2). Specifically, 26 (17.3\%), 68 (45.3\%), 52 (34.7\%), and 17 (11.3\%) students published their undergraduate research project in a medical journal, presented an abstract in a conference, participated in extracurricular research projects, and received extracurricular research education/training, respectively. The most important reasons reported by the students for publishing their $\mathrm{CM}$ research projects (Figure 1) were to improve their curriculum vitae $(18 ; 66.7 \%)$, to help in career progression

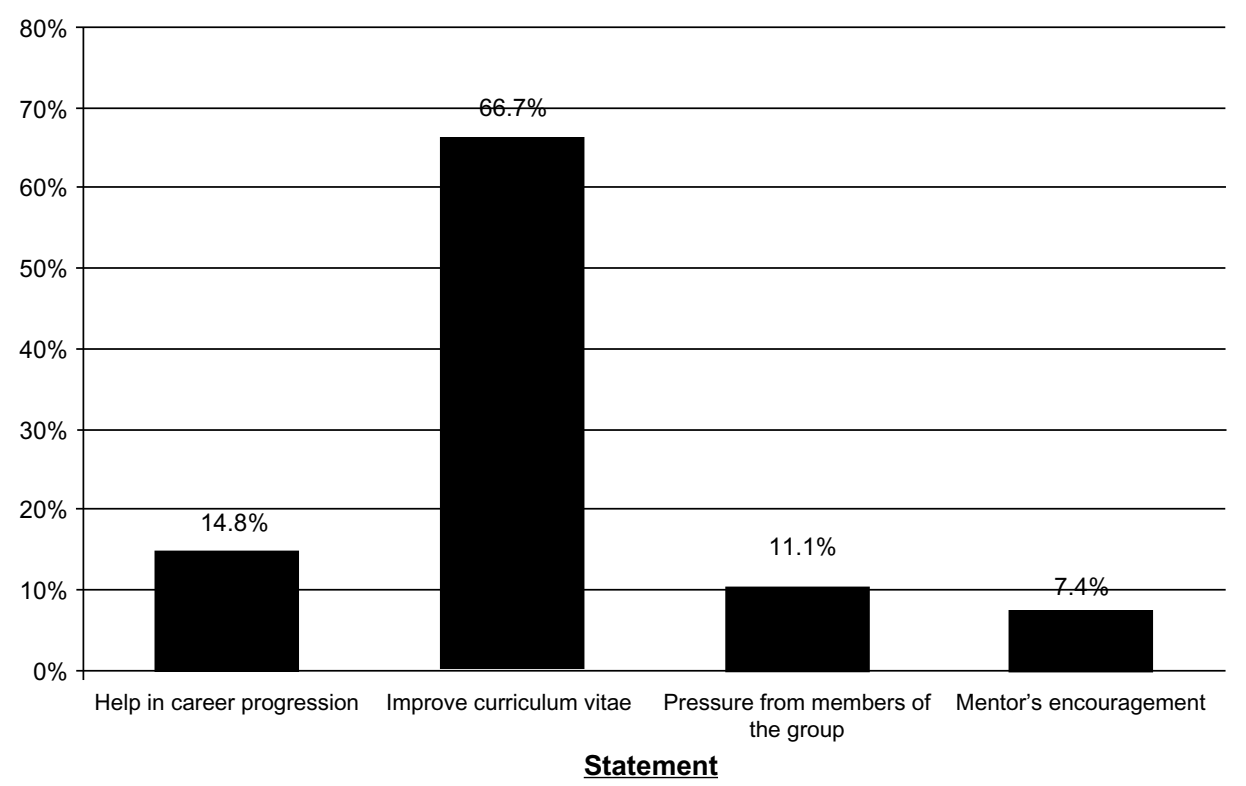

Figure I Reasons for publishing the community medicine research project reported by medical students in Kuwait University during the academic year 20 I2/20I3. 


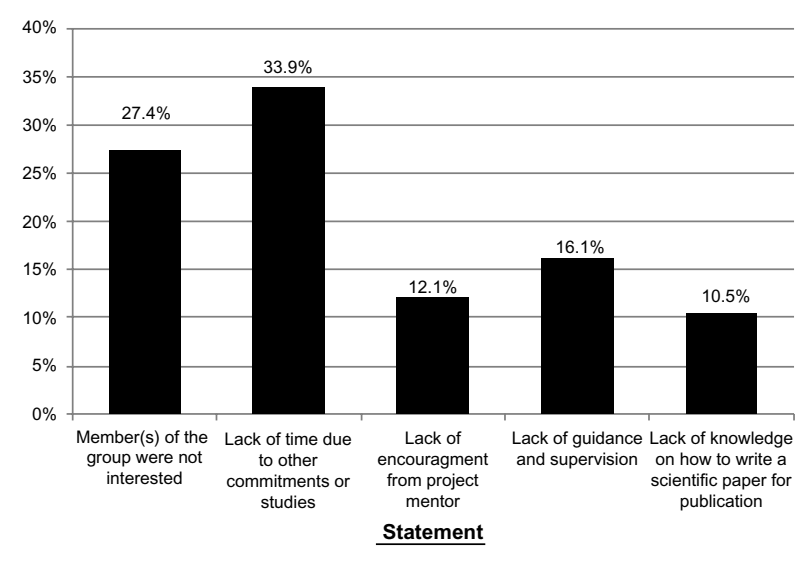

Figure 2 Reasons for not publishing the community medicine research project reported by medical students in Kuwait during the academic year 2012/2013.

Table 3 The association between Kuwait University medical students' sociodemographic and academic characteristics with the participation in extracurricular research activities during the academic year $2012 / 2013$

\begin{tabular}{|c|c|c|c|}
\hline \multirow[t]{2}{*}{ Characteristic } & \multicolumn{3}{|c|}{$\begin{array}{l}\text { Took part in any } \\
\text { extracurricular research } \\
\text { activity }\end{array}$} \\
\hline & $\mathbf{N}$ & (\%) & $P$-value \\
\hline Sex & & & 0.307 б \\
\hline Male & 38 & $(6 \mid .3)$ & \\
\hline Female & 61 & $(69.3)$ & \\
\hline Age (years) & & & 0.1908 \\
\hline$\leq 23$ & 51 & $(6 I .4)$ & \\
\hline$>23$ & 48 & $(71.6)$ & \\
\hline Marital status & & & 0.927 б \\
\hline Married & 22 & $(66.7)$ & \\
\hline Not married & 77 & $(65.8)$ & \\
\hline Year of study & & & $0.110^{8}$ \\
\hline Sixth year & 37 & $(58.7)$ & \\
\hline Seventh year & 62 & $(7 \mid .3)$ & \\
\hline Grade point average (out of 4 ) & & & $0.936^{8}$ \\
\hline$\leq 2.99$ & 81 & $(65.9)$ & \\
\hline$\geq 3.00$ & 18 & $(66.7)$ & \\
\hline Grade in community medicine module & & & $0.265^{\delta}$ \\
\hline$\geq 80 \%$ & 21 & $(75.0)$ & \\
\hline$<80 \%$ & 78 & $(63.9)$ & \\
\hline Decided a future career specialty & & & $0.076^{\zeta}$ \\
\hline Not yet & 47 & $(59.5)$ & \\
\hline Yes & 52 & $(73.2)$ & \\
\hline Preferred future specialty ${ }^{*}$ & & & $0.729 \ddagger$ \\
\hline Surgical & 15 & $(7 I .4)$ & \\
\hline Medical & 21 & $(72.4)$ & \\
\hline Other & 16 & $(76.2)$ & \\
\hline Preferred place of residency ${ }^{*}$ & & & 0.1798 \\
\hline Kuwait & II & $(6 I .1)$ & \\
\hline Outside Kuwait & 41 & $(77.4)$ & \\
\hline Regularly read journal articles & & & $0.003^{\zeta}$ \\
\hline No & 45 & $(55.6)$ & \\
\hline Yes & 54 & $(78.3)$ & \\
\hline
\end{tabular}

Notes: *Out of 71 (47.3\%) participants who have made their decision on specialty; ¿Pearson chi-square; \#linear-by-linear association.
(4; 14.8\%), pressure from members of the research project group (3;11.1\%), and the encouragement of their research mentors $(2 ; 7.4 \%)$. On the other hand, the most important reasons/barriers for not publishing the $\mathrm{CM}$ projects reported by the students (Figure 2) were lack of time due to other commitments or studies $(42 ; 33.9 \%)$, lack of interest either by the participant or other members of his/her project group (34; $27.4 \%)$, lack of guidance and supervision $(20 ; 16.1 \%)$, lack of encouragement from the project's mentor $(15 ; 12.1 \%)$, and lack of knowledge on how to write a scientific article for publication $(13 ; 10.5 \%)$.

The chi-square analysis of the association between participation in extracurricular research activities and sociodemographic and academic characteristics of the students is shown in Table 3. Students who read medical journals regularly were found to have a statistically significant higher participation in extracurricular research activities ( $P$-value 0.003$)$. No other factors were found to be significantly associated with students' participation in these activities.

The students' attitude towards research activities is given in Figure 3. Sixty-three (42.0\%) students believed that research is important during undergraduate education, while $116(77.3 \%)$ believed that it will become important during their future career. In addition, $132(88.0 \%)$ reported interest in clinical-based research, while 104 (69.3\%) students reported interest in laboratory-based research. On the other hand, $18(12.0 \%)$ students reported no interest in research while $5(3.3 \%)$ students believed that research was not relevant to undergraduate medical education. Of the students surveyed, $120(80.0 \%)$ were interested in additional education and training about the process of writing a scientific paper.

Barriers against students' participation in extracurricular research activities are shown in Figure 4. The most important barriers reported by the students that need to be improved so that they can participate more in extracurricular research activities were availability of mentors (score 4.05/5.00), acknowledgement for students' participation in research (score 3.98/5.00), and availability of financial support or grants for students' research (score 3.98/5.00).

\section{Discussion}

Although the overall participation in extracurricular research activities was high, the findings that the majority of $\mathrm{KU}$ medical students did not publish their required undergraduate research project or participate in other extracurricular research activities are similar to some previous studies. ${ }^{15-18}$ 


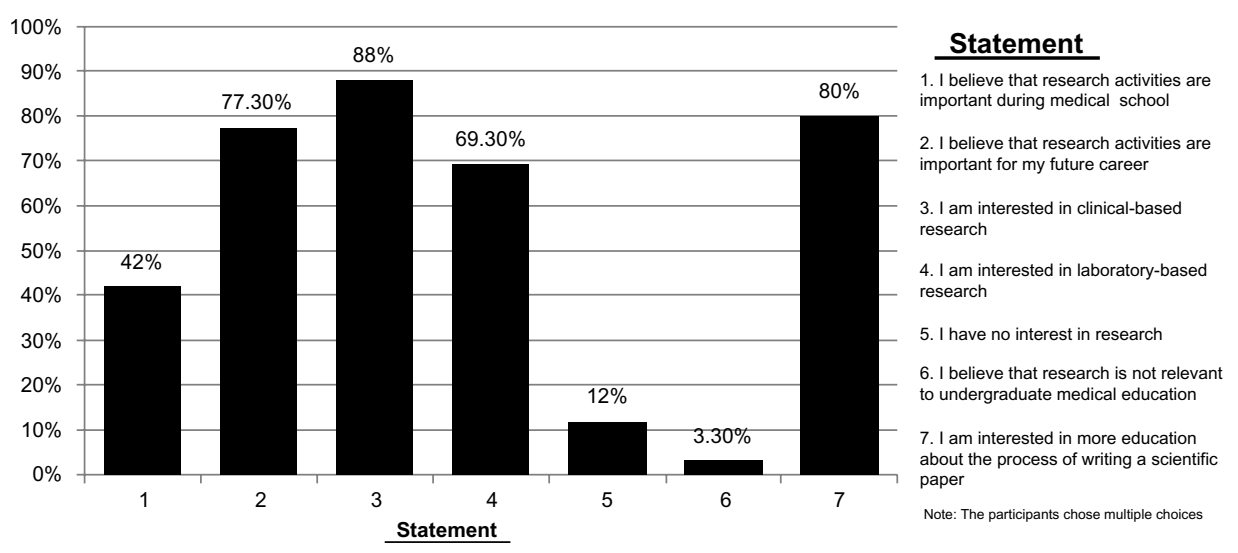

Figure 3 Attitude of medical students in Kuwait University toward research practices and activities during the academic year 20I2/20I3.

For example, the publication rate of students' scientific papers was low in Germany and the UK, ranging from $14 \%$ to $28 \% \cdot{ }^{15,16}$ Nevertheless, a higher rate of publication (range: $41 \%$ to $75 \%$ ) was noted among students from the USA. ${ }^{17,18}$ This difference in the rate of publication of students' research is most probably due to the disparity in the research methodology between the studies; some authors used a questionnaire covering most of the students, while others did a literature search resulting in lower rates of extracurricular research activity. ${ }^{15-17}$ Also, the medical schools' curricular differences might contribute to this difference. For example, Stanford University's School of Medicine provided a good example of successful undergraduate research activities where students were encouraged by funding and teaching staff to conduct research. ${ }^{18}$ This encouragement resulted in $90 \%$ of their students performing research, publications among $75 \%$, and presentations at national meetings among $52 \%$.
The findings of this study that the motivating factors for publishing a paper were mainly to improve the student's personal curriculum vitae and help in career progression were also noted in a study of UK medical students, where $51 \%$ of the students submitted papers for publication to improve their curriculum vitae and $10 \%$ to improve their career progression and academia. ${ }^{15}$ In addition, another study done in the UK revealed that $\mathrm{CV}$ improvement was the main motivator for participation in research and audits among $51 \%$ of medical students. ${ }^{19} \mathrm{On}$ the other hand, $65 \%$ of fourth year Canadian medical students reported that personal interest was their motivation to participate in research activities. ${ }^{10}$ It is important to point out that based on previous studies, although research and publications increase the chances of getting accepted in residency programs, they are not the most important factors used in selecting residents. ${ }^{6-8}$ Hence, students' participation

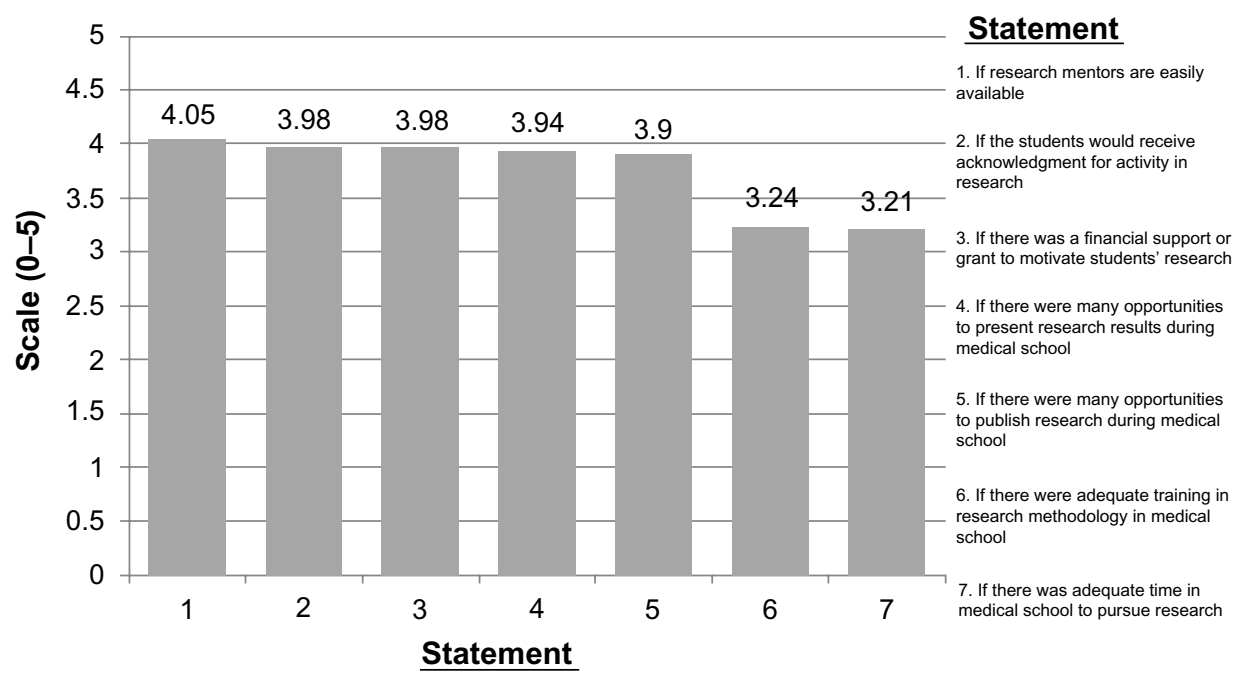

Figure 4 Importance level of factors that can improve undergraduate extracurricular research activities in Kuwait University as perceived by medical students during the academic year 2012/2013. 
in research should not be motivated mainly by improving their $\mathrm{CV}^{6-8}$

Challenges to participation in undergraduate medical research were addressed in previous studies. ${ }^{19-21}$ Availability of research mentors was considered the most important issue that needed to be addressed to improve students' research among our participants. Additionally, lack of time was the most important reason reported by our students for not publishing papers. This aspect also proved to be an important barrier against conducting research among Brazilian medical students. ${ }^{20}$ Likewise, medical students in the UK reported time constraints $(74 \%)$ as the most important obstacle against participation in research and audits, as previously reported. ${ }^{19}$ Such barriers could be resolved by establishing summer research electives, research interest groups, and providing sufficient time for research activities during the undergraduate medical curriculum. ${ }^{22-24}$ Research mentorship should also be encouraged among faculty staff, possibly by funding mentors, and the importance of extracurricular students' research to the publication output of the academic institute should be highlighted. ${ }^{16}$

In Portugal, male students were twice as likely to participate in extracurricular research activities than females, but this was not the case among our participants; the only sociodemographic or academic characteristic that was found to be associated with participation in extracurricular research activities was reading journal articles regularly. ${ }^{25}$ The most probable explanation for this association is that students who read scientific papers have better skills in searching the literature, better understanding of the basic steps of writing a research article, and had more interest in academic careers. Nevertheless, being involved in more research activities can be a reason for reading more scientific journals.

Although less than $20 \%$ of medical students in $\mathrm{KU}$ reported that they are interested in a future specialty that offers more research opportunities, the majority of them reported that research activities were important for their future career. ${ }^{26}$ Moreover, most of the participants were interested in more education about the process of writing scientific papers, and only $12 \%$ reported no interest in research. This interest should be utilized by medical educators and students' mentors in KU to improve the research activities and productivity of their students.

The major limitations of this study are that it is crosssectional, questionnaire-based, and self-reported, which can result in recall and responder biases. Also, some of our participants completed their CM course a few months before data collection; hence they might not have had sufficient time to publish their findings.

\section{Conclusion}

Despite the lack of adequate support, extracurricular research activities among medical students of KU were comparable to students from other countries. Barriers for these activities should be addressed by KU medical educators in order to enhance research activities among the students.

\section{Disclosure}

The authors have no conflicts of interest to declare.

\section{References}

1. Frishman WH. Student research projects and theses: should they be a requirement for medical school graduation. Heart Dis. 2001;3: $140-144$.

2. Houlden RL, Raja JB, Collier CP, Clark AF, Wuagh JM. Medical students' perceptions of an undergraduate research elective. Med Teach. 2004;26:659-661.

3. Burgoyne LN, O'Flynn S, Boylan GB. Undergraduate medical research: the student perspective. Med Educ Online. 2010;15.

4. Seymour E, Hunter AB, Laursen SL, DeAntoni T. Establishing the benefits of research experiences for undergraduates in the sciences: First findings from a three-year study. Sci Ed. 2004;88:493-534.

5. Murdoch-Eaton D, Drewery S, Elton S, et al. What do medical students understand by research and research skills? Identifying research opportunities within undergraduate projects. Med Teach. 2010;32:e152-e160.

6. Green M, Jones P, Thomas JX Jr. Selection criteria for residency: results of a national program directors survey. Acad Med. 2009;84: $362-367$.

7. Sinha S, Sinha A, Sinha S, Bhan C, McConnachie A, Knowles CH. Selection matters-a regional survey of UK consultant opinion on selection into postgraduate surgical and medical training. J Surg Educ. 2010;67:85-94.

8. Marwan Y, Ayed A. Selection criteria of residents for residency programs in Kuwait. BMC Med Educ. 2013;13:4.

9. Pruskil S, Burgwinkel P, Georg W, Keil T, Kiessling C. Medical students' attitudes towards science and involvement in research activities: a comparative study with students from a reformed and a traditional curriculum. Med Teach. 2009;31:e254-e259.

10. Siemens DR, Punnen S, Wong J, Kanji N. A survey on the attitudes towards research in medical school. BMC Med Educ. 2010;10:4.

11. Karim J,Al-Saraji M, Al-Mousawi F, et al. Knowledge and self-reported practice of universal precautions among Kuwait University medical students in their clinical years. Med Princ Pract. 2012;21:328-333.

12. Marwan Y, Al-Saddique M, Hassan A, Karim J, Al-Saleh M. Are medical students accepted by patients in teaching hospitals? Med Educ Online. 2012;17:17172.

13. Karim JA, Marwan YA, Dawas AM, Akhtar S. Self-confidence of medical students in performing clinical skills acquired during their surgical rotation: Assessing clinical skills education in Kuwait. Saudi Med J. 2012;33:1310-1316.

14. Almutar S, Altourah L, Sadeq H, Karim J, Marwan Y. Medical and surgical ward rounds in teaching hospitals of Kuwait University: students' perceptions. Adv Med Educ Pract. 2013;4:189-193.

15. Griffin MF, Hindocha S. Publication practices of medical students at British medical schools: experience, attitudes and barriers to publish. Med Teach. 2011;33:e1-e8. 
16. Cursiefen C, Altunbas A. Contribution of medical student research to the Medline-indexed publications of a German medical faculty. Med Educ. 1998;32:439-440.

17. Dyrbye LN, Davidson LW, Cook DA. Publications and presentations resulting from required research by students at Mayo Medical School, 1976-2003. Acad Med. 2008;83:604-610.

18. Jacobs CD, Cross PC. The value of medical student research: the experience at Stanford University School of Medicine. Med Educ. 1995;29:342-346.

19. Nikkar-Esfahani A, Jamjoom AA, Fitzgerald JE. Extracurricular participation in research and audit by medical students: opportunities, obstacles, motivation and outcomes. Med Teach. 2012;34:e317-e324.

20. de Oliveira NA, Luz MR, Saraiva RM, Alves LA. Student views of research training programmes in medical schools. Med Educ. 2011;45:748-755.

21. Tagal J. Difficulties in undergraduate medical research. Clin Teach. 2007;4:2-5.
22. Zier K, Friedman E, Smith L. Supportive programs increase medical students' research interest and productivity. J Investig Med. 2006;54:201-207.

23. Mabvuure NT. Twelve tips for introducing students to research and publishing: a medical student's perspective. Med Teach. 2012;34:705-709.

24. Lawson McLean A, Saunders C, Velu PP, Iredale J, Hor K, Russell CD. Twelve tips for teachers to encourage student engagement in academic medicine. Med Teach. 2013;35:549-554.

25. Salgueira A, Costa P, Gonçalves M, Magalhães E, Costa MJ. Individual characteristics and student's engagement in scientific research: a crosssectional study. BMC Med Educ. 2012;12:95.

26. Al-Fouzan R, Al-Ajlan S, Marwan Y, Al-Saleh M. Factors affecting future specialty choice among medical students in Kuwait. Med Educ Online. 2012;17:1-7.

\section{Publish your work in this journal}

Advances in Medical Education and Practice is an international, peerreviewed, open access journal that aims to present and publish research on Medical Education covering medical, dental, nursing and allied health care professional education. The journal covers undergraduate education, postgraduate training and continuing medical education including emerging trends and innovative models linking education, research, and health care services. The manuscript management system is completely online and includes a very quick and fair peer-review system. Visit http://www.dovepress.com/testimonials.php to read real quotes from published authors.

Submit your manuscript here: http://www.dovepress.com/advances-in-medical-education-and-practice-journal 